\title{
Na cena em primeira pessoa: percursos e modos de atuação no Projeto Magdalena Marisa Naspolini
}

Resumo

Este artigo analisa o percurso criativo e os modos de atuação presentes em dois espetáculos de atrizes/diretoras vinculadas ao Projeto Magdalena nos quais encontramos uma forte presença da subjetividade como propulsora do ato criativo. Para tanto, dialogamos com as noções de "sujeito nômade", da filósofa feminista Rosi Braidotti, e "partir de si", expressão que gerou reflexões junto à comunidade filosófica feminina

Diotima, buscando pensar sobre os caminhos da(s) subjetividade(s) feminina(s) na cena contemporânea.

Palavras-chave: Subjetividade nômade; Mulheres; Projeto Magdalena.

\section{Abstract}

This article analyses the creative path and modes of acting present in two performances by actresses/directors connected to The Magdalena Project where we find a strong presence of subjectivity as the drive for the creative act. We propose a dialogue with the notions of "nomadic subject", by feminist philosopher Rosi Braidotti, and "start from oneself", expression that generated reflections within the philosophical female community Diotima, in the search for ways of thinking about the female subjectivity(s) in the contemporary scene.

Keywords: Nomadic subjectivity; Women; The Magdalena Project.

1 Marisa Naspolini é doutora em teatro pela UDESC. É atriz, professora e analista de movimento pelo Laban Institute de Nova York. Coordena o Vértice Brasil, encontro e festival de teatro ligado ao Projeto Magdalena. É presidente da Áprika Cooperativa de Arte. Integra o Baobah - estúdios de autocriação. 


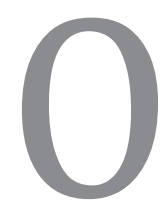

Projeto Magdalena (The Magdalena Project) é uma rede internacional de mulheres de teatro e performance que surgiu como um espaço de discussão, troca e apoio mútuo visando gerar visibilidade ao trabalho artístico de mulheres. Desde sua criação, no País de Gales, em 1986, o projeto se mantém engajado em fomentar a consciência da contribuição da mulher para o teatro e em apoiar a exploração e a pesquisa através de uma oferta concreta de oportunidades de intercâmbio, agregando praticantes de teatro de várias partes do mundo, sejam companhias, artistas individuais ou acadêmicas, que encontram ali um espaço crítico de discussão e reconhecimento do seu trabalho. Sua organização em rede gera uma articulação horizontal entre suas participantes que permite ações cooperativas que se desviam de padrões hierárquicos verticais para inventar e construir novas formas de organização adequadas a essa comunidade específica.

Encontramos em seu interno uma pluralidade de propostas estéticas que estão longe de configurar um desenho hegemônico seja do ponto de vista dos percursos criativos ou dos modos de produção. A diversidade geográfica, geracional, estética e cultural implica na existência de poucos elementos em comum entre suas integrantes além do fato de serem artistas mulheres praticantes de teatro. No entanto, é possível vislumbrar algumas tendências e, principalmente, alguns aspectos recorrentes na produção espetacular de suas integrantes, que é o que proponho trazer à luz neste breve artigo. Meu foco estará direcionado para refletir sobre a presença da subjetividade no trabalho de duas atrizes/diretoras vinculadas à rede, utilizando o conceito de subjetividade nômade e a noção de "partir de si" para pensar sobre como estas relações reverberam na cena, particularmente em espetáculos solo.

O conceito de sujeito nômade proposto pela filósofa italiana Rosi Braidotti se apresenta como um caminho para pensar sobre a subjetividade feminina de maneira diver- sa, inventando estruturas de pensamento, imagens e modos de pensar que sejam compatíveis com as novas formas de estar no mundo. Esta necessária reinvenção implica em renunciar a modelos e hábitos de pensamento estabelecidos em busca de outras visões possíveis da subjetividade humana, que abarquem identidades complexas e multi-dimensionadas (Braidotti, 2002a, p. 9), superando a noção de sujeito essencializado para dar vazão a uma perspectiva identitária múltipla, que permita repensar os binarismos e concepções dualísticas e hierarquizadas de mundo. Este entendimento de sujeito dá prioridade à experiência (ou à política da vida cotidiana), e reforça o papel da afetividade, do desejo e da sexualidade em suas interrelações com o poder, a inclusão/exclusão e a resistência.

O nomadismo de Braidotti não consiste em estar em eterno deslocamento ou em não ter lar, mas em ser capaz de recriá-lo em qualquer lugar. "O nômade carrega seus pertences pessoais aonde quer que vá e pode recriar sua base onde for" (Braidotti, 1994, p. 22). Mas o que define o estilo nômade é a predisposição à subversão do conjunto de convenções, a resistência a modos de pensamento e comportamento codificados, não o ato literal de viajar.

Com a noção de sujeito nômade, a filósofa italiana apresenta uma figuração teórica ${ }^{2}$ para a subjetividade contemporânea, comprometida com a tarefa de subverter visões convencionais e representações do humano, mais especificamente da subjetividade feminina. Seu nomadismo não se define como uma fluidez sem limites, mas, sobretudo, como a consciência da não fixidez dos limites. É o desejo de continuar a transgredir.

O sujeito nômade é um mito, uma
invenção política que me permite
pensar a fundo circulando através de
categorias e de níveis de experiência
dominantes: tornar as fronteiras inde-

2 Braidotti prefere o termo "figuração" à metáfora, entendendo que a figuração é um diagrama de relações de poder. "A figuração não é metáfora, mas um instrumento cartográfico de navegação em águas tempestuosas de um presente cujo horizonte não está mais romanticamente velado e incerto, mas brutal e claramente em pedaços. Uma figuração é uma cartografia, isto é, um mapeamento político da atualidade." (Braidotti, 2002, p. 15) 
finidas sem queimar as pontes. [...] Nem todos os nômades viajam pelo mundo. Algumas das viagens mais extraordinárias podem ser feitas sem mover-se fisicamente de seu habitat. $\mathrm{O}$ estado nômade, mais do que pelo ato de viajar, é definido por uma tomada de consciência que sustenta 0 desejo de derrubar convenções dadas: é uma paixão política pela transformação ou pela mudança radical. (Braidotti, 2002, p. 14, trad. nossa).

Para Braidotti, ser nômade significa viver em transição, não no sentido de não poder ou não querer criar bases estáveis e seguras, "identidades que nos permitam nos sentir à vontade dentro de uma comunidade", mas de não considerar nenhuma identidade como permanente. O nômade é uma entidade transgressiva cuja natureza transitória é o motivo pelo qual ele pode fazer conexões. "A política nômade é uma questão de laços, de coalisões, de interconexões" (Braidotti, 2002, p. 55-56). Ela ressalta as características de transmobilidade e a capacidade de mover-se através de e entre fronteiras de forma interconectada como geradoras de um espaço intersticial onde novas formas de subjetividade podem ser exploradas.

A atriz argentina Ana Woolf criou seu primeiro espetáculo solo, Semillas de Memoria (Sementes de Memória) (2000), no "exílio", durante uma sucessão de estadias na Dinamarca, junto ao Odin Teatret, sob direção da atriz Julia Varley. Ana Woolf vem de uma tradição de teatro baseado no texto, com formação na Escola de Artes Dramáticas de Buenos Aires, dirigida por Julio Baccaro, e paralelamente desenvolveu treinamento na "gramática dos pés" 4

\footnotetext{
3 A autora propõe que a posição feminista nômade abarque a coexistência de diversas representações do feminino já explicitadas por outras autoras (De Lauretis, Butler, Irigaray, Wittig, entre outras) e sua flexibilidade seja um elemento impeditivo de novas divisões na prática feminista, mas, ao mesmo tempo, reafirme a diferença entre as muIheres, evitando qualquer pensamento generalizante e reforçando a ideia de diferença dentro de cada sujeito. Proposta em alguns aspectos semelhante é feita pela indiana Gayatri Spivak, criadora do termo "essencialismo estratégico", que explica a necessidade de o movimento feminista assumir uma forma de "essencialismo temporário" para atuar como uma unidade, apesar de suas diferenças internas.

4 O método criado por Tadashi Suzuki consiste na ênfase do movimento na parte inferior do corpo e dos pés, com atenção especial à zona pélvica, centro de gravidade do ator. A técnica direciona a energia do corpo para baixo, através de um treinamento psicofísico intenso que associa exercícios verbais, trabalhando exaustão e imobilidade no corpo e na voz.
}

de Tadashi Suzuki. Hoje, a atriz integra a equipe pedagógica da ISTA (International School of Theatre Anthropology), dirigida por Eugenio Barba, e vive em Buenos Aires, onde dirige, atua, desenvolve um trabalho pedagógico e assina a direção artística da Rede Magdalena Segunda Generación. O termo exílio é utilizado por ela (referindo-se à sua longa temporada na Europa), ainda que Woolf se configure melhor na noção de migrante temporária ou ainda de sujeito nômade.

A diferença principal entre a migrante e a exilada, na definição de Braidotti, seria que a migrante tem um destino certo, desloca-se de um ponto a outro com um objetivo bem preciso, com frequência econômico, e tende a se apoiar em seus valores "natais", enquanto tenta se adaptar àqueles do ambiente anfitrião. $\mathrm{O}$ exilado estaria marcado pela separação radical de seu ponto de partida, frequentemente devido a razões políticas, e sua situação implica em certo vagar por diferentes lugares com o sentimento de ausência de pátria, de moradia e de um ponto fixo de referência (Braidotti, 2002a, p. 20). O nômade, por outro lado, se posiciona pela renúncia e desconstrução de qualquer identidade fixa. $\mathrm{O}$ sujeito nômade é dotado de uma consciência periférica, rejeita as regras pré-estabelecidas, sua memória está ativada contra a corrente. Seu estilo tem a ver com transições e passagens, sem destinos pré-determinados ou terras natais perdidas. Braidotti propõe que a ideia de nomadismo ativo seja assumida como a figuração central da subjetividade feminina pós-moderna, reforçando uma postura política e uma opção de vida. Nesse sentido, o sujeito nômade não se apresenta como vítima da falta de lar ou de um deslocamento obrigatório, mas exprime o desejo de uma identidade feita de transições e deslocamentos, e distanciada de uma ideia de unidade essencial (Braidotti, 2002).

Semillas de Memoria é um espetáculo sobre ausência. Entrecruzando lírico e épico, a atriz une memórias pessoais e autobiografia a um discurso histórico sobre os desaparecidos na Argentina. As diversas au- 
sências - ausência do pai morto e ausência dos corpos para serem velados e enterrados - se fundem em uma cena que se apoia na força da presença através de uma persona que é e não é personagem de si mesma para gerar resistência e identidade. $\mathrm{O}$ conflito da ausência/presença constitui um dos pilares para a poética do espetáculo. A distância de casa e de aspectos da cultura argentina leva a atriz a lidar com o espaço de trabalho e as inúmeras horas passadas em treinamento solitário como uma espécie de refúgio onde é possível "voar", mergulhar em um intenso e exaustivo trabalho físico e entrar em mundos imaginários que lhe permitem estar em contato com as pessoas que lhe são caras.

Estar na Dinamarca, que paradoxalmente é uma geografia que não me trazia recordações, lembranças, não tinha um café que me lembrasse meu pai, uma rua que me lembrasse Buenos Aires, pelo contrário, era uma oposição total. Como é possível que estando longe eu tenha tido aparições, lembranças e memórias da minha infância, das minhas ausências, como um corpo desaparecido... Eu me sentia também desaparecida em uma nova cultura. Desaparecida na cultural teatral como a do Odin. Quando a gente chega ali, não tem identidade. [...] Eu fazia training de Suzuki, trabalhava com disciplina, e depois colocava música latina pra dançar, pra não fazer training, pra nada, pra esquecer... Pra esquecer da disciplina, da forma, da técnica... (Woolf, 2012, entrevista concedida a Marisa Naspolini).

Woolf fala do treinamento na técnica de Suzuki55, que já trazia incorporada há alguns anos, como a descoberta inesperada de um valor que a acompanhava onde quer que fosse e lhe permitia, falando ou não a língua local, ter um instrumento para pro-

5 Sobre o treinamento em Suzuki, a atriz comenta: "a técnica de Tadashi Suzuki me deu as raizes dos meus pés e a voz. Um alojamento. Um centro de energia que me protege, a potência do corpo e o máximo controle. [...] Ele [Suzuki] criou a técnica chamada 'a gramática dos pés', ele diz que 0 ator contemporâneo perdeu a base de seus pés, os fechou dentro de sapatos apertados, e cai, cambaleia, caminha sem consciência. Suzuki cria exercícios em diferentes níveis, como as caminhadas e marchas que vocês vão ver agora, com uma música fixa, e de novo a palavra chave: Ritmo." (Trecho do espetáculo Detrás del telón). teger-se de qualquer tipo de situação triste ou dolorosa. "Eu podia entrar em um quarto vazio e não me perder em meio ao caos de milhares de possibilidades. Eu tinha o um, dois, três, o início, meio e fim de uma ação específica que me ajudava" (Woolf, 2006, p. 138, trad. nossa).

A atriz se refere especificamente à disciplina de uma técnica feita de constrições rigorosas e de respeito às regras com passos codificados e fixados que lhe dava segurança e um chão firme a partir do qual poderia improvisar e criar. Aos poucos, estimulada pela direção, a atriz foi agregando ao treinamento elementos da música latina, como a cadência ritmada e uma espécie de densidade emocional que não encontrava na música oriental, e criou uma série de exercícios combinando o treinamento japonês e os ritmos latino-americanos, de forma a explorar a oposição entre a firmeza e a não dissociação presentes no Suzuki e a leveza e o movimento fluido presentes nos ritmos latinos. Enraizamento nos pés, respiração abdominal, oposição na coluna, visão periférica, expansão da energia, repetição e disciplina são alguns dos princípios presentes no treinamento personalizado que ela inventou a partir de um espaço de memória "entre geografias", situado em algum lugar entre Japão, Dinamarca e Argentina. Talvez um espaço inscrito nas nuvens, parafraseando Julia Varley $^{6}$ e imaginando um possível terceiro lugar poético que unisse memórias e geografias tão distintas entre si.

Cristina Castrillo também é argentina, da província de Córdoba, e fundou no ano de 1980 o Teatro delle Radici (Teatro das Raízes) em Lugano, na Suíça, onde mantém uma companhia e atua como atriz, pedagoga e diretora. Castrillo foi também cofundadora do grupo argentino Libre Teatro Libre que, nos anos 1970, se notabilizou

\footnotetext{
6 Em palestra proferida durante o Vértice 2010 (encontro e festival internacional de teatro feito por mulheres), em Florianópolis, cujo tema era Travessia, com foco nas relações interculturais na produção teatral, ela disse, referindo-se ao Transit Festival denominado Roots in Transit, realizado em 2004 na Dinamarca: "Quando eu fiz o Transit sobre as raízes, eu falava que as raízes estão no ar, não na terra. Que existe essa possibilidade se você viaja o tempo todo. Então as raízes estão nas nuvens... É uma outra sensação do cultural." (Varley, 2010).
} 
pelo espírito anárquico e irreverente, pela estrutura interna baseada na criação e direção coletiva e, principalmente, pela intensa atuação política no conturbado contexto latino-americano. Em 1975, ameaçado pela ditadura, o grupo partiu para a Venezuela e seus membros se dispersaram por diversos países da Europa e da América Latina. Após cinco anos de errância e trabalhando só, a atriz/diretora se estabeleceu na Suíça italiana, onde vive e trabalha até hoje.

Ela se refere ao exílio como "uma enorme e potente solidão, além de uma dor profunda" que, de forma violenta, determinou os rumos de seu trabalho artístico (Castrillo, 2010, p. 132-133). A solidão permeou seu percurso como atriz/diretora autodidata que se viu sem país, sem amigos, sem nada do que lhe parecia significativo e fundamental até então e, imersa na ausência, continuou a inventar exercícios teatrais na tentativa de elaborar uma via criativa na qual pudesse se reconhecer.

É claro que havia o sentimento de exilada. Mas eu sabia que o que eu estava procurando era outra coisa. Eu trabalhei por cinco anos só e exclusivamente comigo mesma. O exílio se sucedeu de uma cidade a outra até que em um determinado momento senti a necessidade de ter um lugar para ficar. Eu vim para Lugano por acaso, mesmo que na verdade eu tenha chegado lá porque eu não sabia mais para onde ir. (Castrillo, 2010, p. 132-133, trad. nossa).

Castrillo nunca trabalhou com um(a) diretor(a), sua trajetória se manteve autodidata, com exceção do período no Libre Teatro Libre, o que significa que no decorrer dos anos ela inventou seu próprio modo de trabalhar. "Sempre dirigi o meu trabalho em primeira pessoa. Nunca me perguntei: sou uma atriz ou uma diretora?" O espetáculo solo Umbral [Limiar], estreado em 1999, surgiu não de um pensamento ou de uma ideia sobre uma criação nova, mas da "necessidade de moldar ativamente o produto de uma experiência de trabalho que comprometeu uma vida inteira" (Castrillo, 2001). Apesar de ser um espetáculo onde a atriz está só na cena, ela ressalta a importância das atividades pedagógicas e criativas envolvendo diversos atores, além da força da cultura de grupo, que ajudaram a construir sua experiência pessoal.

Em Umbral, a atriz/diretora reflete sobre sua jornada criativa e desenha um mapa formado por imagens de encontros, de incertezas, de becos sem saída que impactaram e transformaram sua própria vida. Em uma narrativa metateatral que é física e ao mesmo tempo verbal, ela fala de teatro e do ofício teatral através de uma linguagem que obedece a duas lógicas binárias, que ela denomina "explicativo-reflexiva" e "especificamente teatral". A atriz reproduz os pontos que considera essenciais de sua visão na própria pele, desnudando o fazer teatral com uma abordagem reflexiva, nascida do contato direto com a prática, que demandou encontrar uma forma ativa, orgânica e emotiva de compartilhar com o espectador alguns momentos de "suspiro da alma" (Castrillo, 2001). Para isso, desenvolveu um mecanismo de precisão que possibilitasse fazer as transições entre dois modos de pensar, cuja passagem ela considera o aspecto mais difícil na elaboração da estrutura do espetáculo. A coexistência de duas lógicas, de duas formas de se colocar cenicamente, como se fossem "duas almas", a obriga a manter dois níveis de atuação simultaneamente, um nível mental e outro baseado na reação. $\mathrm{Na}$ cena, isso se traduz em uma mudança na gestualidade e na forma de se relacionar com o público.

A introspecção e a solidão estão na base de seu trabalho e a memória funciona como um tema subjacente recorrente e exerce um papel fundamental. Memória não como "reprodução de fatos" ou referência a recordações, mas como "uma geografia pessoal desconhecida com a qual e na qual nos manifestamos, atuamos, representamos e transmitimos"7. A diretora argentina prefere usar a palavra introspecção, ao invés de memória, e reforça que seu desejo não

7 Texto sobre o espetáculo no site do grupo www.teatrodelleradici.it 
é buscar uma história pessoal emocional, mas encontrar a chave para destravar um "senso" de memória. Esta busca está diretamente relacionada a um contato íntimo com aspectos do universo pessoal e a um processo permanente e profundo de reconhecimento de si.

Nos dois casos citados, coincidentemente de duas artistas argentinas que se estabeleceram (transitoria ou permanentemente) na Europa, podemos ver uma imbricação entre o percurso político e o percurso pessoal que resultou em modos de criação nos quais a subjetividade é imperativa na forma de criar materiais e compor a cena. Aqui a ideia de resistência se impõe como a batalha cotidiana "de se proteger quem se é" (Castrillo, 2005).

$\mathrm{O}$ formato monológico experienciado por ambas favorece o mergulho subjetivo e a emergência de uma voz autoral. Com a reivindicação de uma dimensão pessoal e do que a filósofa italiana Luisa Muraro chama de "partir de si" (retomando e renovando o eterno "o pessoal é político" dos anos 1960) $)^{8}$, a atriz/performer de solo revela seu desejo de expressar sua própria vontade na cena, ao invés de atuar como intermediária da vontade de um outro. Citando o diretor e pesquisador André Carreira (2010, p. 5), "sem escudo de proteção, a atriz cruza o 'deserto da solidão' com o objetivo de encontrar o outro e de tornar visível sua condição humana através da encenação da ficção e do real".

Em um artigo no qual discorre sobre os solos de dança na contemporaneidade (e também em outros momentos da história), a pesquisadora e professora italiana Eugenia Casini Ropa faz uma análise que poderia perfeitamente ser aplicada ao trabalho solo no teatro e na performance. Ela se refere à necessidade expressada por muitos bailarinos de elaborar sozinhos novas formas e temáticas que serão leva-

8 A força de "partir de si" surge, na história do feminismo, da urgência de derrubar o hábito feminino de pensar a partir de um outro ou de assumir uma imagem de sujeito traçada a partir de uma ideia de outro. Não se trata de uma prática individualista ou narcisista, mas de um movimento de descentramento e desconstrução do sujeito em direção a um pensamento libertário que dialogue com as múltiplas identidades e diferenças (Sartori, 1996; Muraro, 1996). das ao trabalho com o grupo mais tarde. O trabalho solitário permitiria, além de velocidade, praticidade e maior profundidade no processo criativo, uma espécie de liberdade na forma de explorar aspectos psicológicos e autobiográficos e na criação de parceiros imaginários.

Muitos dançarinos sentem a neces-
sidade do isolamento, do silêncio,
da suspensão do julgamento e da re-
flexão trabalhosa sobre os próprios
meios e os próprios fins. Querem
criar um face a face com o próprio
material concreto básico, seu corpo-
mente, que se libera do ruído midiá-
tico e da inquietude empresarial para
viver a experiência artística psicofí-
sica mais pobre e direta, e ao mesmo
tempo, talvez, mais rica e total. (Ca-
sini Ropa, 2009, p. 69).

Este isolamento, no contexto do teatro experimental, parece estar ligado à necessidade do ator/atriz/performer encontrar a sua própria linguagem tendo como principal recurso a exploração da sua subjetividade. Ideologicamente, a opção pelo trabalho solo, ao mesmo tempo em que parece reforçar o individualismo próprio da pós-modernidade, carrega em si um andar contra a corrente à medida que se dedica a uma produção artística artesanal e de profundidade introspectiva.

A ideia e a prática do "partir de si" traz a perspectiva de viver fiel a si mesmo. É uma prática criada para lutar contra a imposição feita tanto a homens quanto a mulheres, mas particularmente a mulheres, de partir daquilo que outros já estabeleceram como verdadeiro e justo. Muraro chama a atenção para um aspecto de risco que a própria expressão esconde/revela. "O que quer dizer partir ou partir de?" Distanciar-se de algo ou alguma coisa para ir a algum lugar, dividir, separar. Ao mesmo tempo, partir implica em um movimento inicial em direção a. A expressão, portanto, une dois significados diversos, afastar-se e dar início, separar-se e originar: para encontrar o início, 
é preciso separar-se (Muraro, 1996, p. 13).

Muraro propõe pensar a relação do "partir de si" com o próprio nascimento. Uma separação cheia de incógnitas e promessas: o momento da perda da segurança do corpo materno para um lançar-se nas precárias relações entre humanos, começando pela própria mãe. $\mathrm{O}$ "partir de si" assumiria, então, o significado de renovação do movimento de vinda ao mundo, criando uma correspondência com a "partida arriscada e promissora" que é o nascimento. Seria a criação cênica "a partir de si", tão frequente na produção artística contemporânea feita por mulheres, um desejo e uma necessidade para a revelação de uma nova subjetividade, ainda em processo de afirmação?

Nesta perspectiva, assim como na ética nômade de Braidotti, o outro é cada vez menos espelho de mim e cada vez mais diverso de mim. A diferença - e o respeito à diferença - é o terreno desta subjetividade emergente, que vem sendo (re)construída por vozes minoritárias que buscam representatividade nos discursos dominantes. Podemos pensar sobre que representações do feminino emergem destas práticas. Encontramos nos trabalhos descritos neste artigo uma valorização da dimensão afetiva nas práticas políticas, artísticas e sociais destas artistas, um desejo de conexão entre teoria e prática, uma necessidade de envolver o corpo e os afetos na teoria, uma tentativa de união entre mundo e casa. Braidotti sugere a figuração da subjetividade nômade para pensar a condição humana, e particularmente a feminina, em um modo nãohierárquico e multidiferenciado, no qual estas junções sejam possíveis (BRAIDOTTI, 1994). Assim, o nomadismo é entendido como condição existencial e estilo de vida e de pensamento: um modo de pensar e de criar que privilegia a intuição e a experiência encarnada, inscrita no corpo, (des) enraizada na terra. 


\section{REFERÊNCIAS}

BRAIDOTTI, Rosi. Nuovi soggetti nomadi. Roma: Luca Sossella Editore, 2002a.

BRAIDOTTI, Rosi. Nomadic subjects: embodiment and sexual difference In contemporary feminist theory. New York: Columbia University Press, 1994.

CARREIRA, André. Una mirada sobre territorios de soledad. In: DIP, Nerina. Solo en la escena. In: Cuadernos de Picadero. Buenos Aires: Instituto Nacional de Teatro, ago. 2010. n. 20.

CASINI ROPA, Eugenia. O solo de dança no século XX: entre proposta ideológica e estratégia de sobrevivência. In: Urdimento, Florianópolis, n. 12, p. 61-72, 2009.

CASTRILLO, Cristina. Alcuni elementi sul processo di Umbral. Conferência realizada no Festival Internazionale di Santo Domingo em 2001.

CASTRILLO, Cristina. Spazi di rappresentazione. Conferência realizada no IX Incontro di Donne di Iberoamerica nell'Arte, 2005.

CASTRILLO, Cristina. Forum Actrices y directoras. In: On tip toe a Santa Clara. Roma: Bulzoni Editore, 2010.

MURARO, Luisa. Partire da sé e non farsi trovare... In: La sapienza di partire da sé / Diotima Napoli: Liguori, 1996.

SARTORI, Diana. Nessuno è l'autore della propria storia: identità e azione. In: La sapienza di partire da sé / Diotima. Napoli: Liguori, 1996

VARLEY, Julia. Magdalena 25 anos: identificando o legado e o desafio. Florianópolis, 2010. Palestra realizada no VÉRTICE BRASIL 2010 em 23 jul. 2010.

WOOLF, Ana. Borders, constrictions and limits. In: The Open Page. Women - Theatre Practice, n. 11. Holstebro: Odin Teatrets Forlag, mar. 2006.

WOOLF, Ana. Entrevista concedida a Marisa Naspolini. Florianópolis, 15 jul. 2012. 